\title{
Neki metodološki problemi u savremenom istraživanju socijalnih femininativa u srpskom jeziku*
}

\begin{abstract}
Tomić Svetlana, Neki metodološki problemi u savremenom istraživanju socijalnih femininativa u srpskom jeziku (Some Methodological Problems in Contemporary Research of Social Femininatives in the Serbian Language). "Poznańskie Studia Slawistyczne" 20. Poznań 2021. Publishing House of the Poznań Society for the Advancement of the Arts and Sciences, Adam Mickiewicz University, pp. 323-346. ISSN 2084-3011.

This work critically examines some epistemological problems of the institutionalized public knowledge of Serbian lingustics and the knowledge of the opposed groups of social and feminist linguists. It also provides attention to some relevant studies of feminine derivational sufixes in the Serbo-Croatian and Croatian language. Under consideration are some crucial methodological issues such as supporting a claim, reliability of evidence, presenting disagreement among sources, and research ethos. The research contributes to the fuller understanding of the problem of social femininatives and to enlarging the types of reference sources. It suggests the need of thorough diachronic and interdisciplinary research which would look at different centuries and show the correlation between macsculine and feminine sufixes, the chronological activisation and geographical distribution of social femininatives, their productivity, archaization and extinction, as well as the newest proposals.
\end{abstract}

KeYwords: Serbian language; Croatian language; social femininatives; historical linguistics

${ }^{*}$ Rana verzija ovog rada, pod naslovom Socijalni femininativi u srpskom (i srpskohrvatskom) jeziku. Priroda jezika, ili priroda normativista? Prilog proučavanju istorijske lingvistike, bila je izložena 25. septembra 2020. godine na Devetoj međunarodnoj naučnoj konferenciji „Jezik, književnost i priroda”, održanoj na Fakultetu za strane jezike Alfa BK Univerziteta u Beogradu. Zahvaljujem Svenki Savić, Jeleni Jovanović Simić, Marjani Stevanović i anonimnim recenzentima i recenzentkinjama na dragocenim napomenama. 


\section{Uvod}

\section{Tema, dosadašnja istraživanja, cilj rada}

Tema ovog rada tiče se metodologije imenovanja društvenog statusa, funkcije ili profesije žena u srpskom jeziku i lingvistici, a zbog razvojnih veza srpskog jezika sa hrvatskim razmatraće se i primeri iz srpskohrvatske i hrvatske lingvistike. Imenice koje pripadaju nominalnim derivatima ili mocionom podrazredu nomina agentis et profesionis označavaju društveni status, funkciju ili profesiju žena. Početkom 21. veka ovaj tip derivata ulazi u srpsku (strukturalnu) lingvistiku pod novim terminom socijalni femininativi (Пипер, Клајн, 2013, 54). U nekim novijim radovima (Драгићевић, Утвић, 2019, 188) socijalni femininativi su značenjski izjednačeni sa „moviranim femininumima” (hopић, 1982, 6) iako su to dva različita pojma. Prema objašnjenju Bože Ćorića, „movirani femininumi” ili „femininumi” su mocione izvedenice nastale pomoću muških korelativa (Ћорић, 1982, 6). Od početka 21. veka feminističke lingvistkinje (interdiciplinarnog i intersekcionalnog polja) u Srbiji usvajaju anglosaksonski termin gender sensitive language, prevode ga kao „rodno osetljiv jezik” (skraćeno ROJ), koristeći slične i srodne izraze (,rodno senzitivan” i „rodno nediskriminativan jezik") ${ }^{1}$. U široj javnosti, teorija i praksa feminističkih lingvistkinja naišli su na negativnu reakciju, tumačeni su kao nepotreban uticaj sa Zapada, dok se retko pominjala činjenica o tome da je srpski jezik oduvek bio rodno osetljiv(v. i cf. Savić, 2009, 5-35; Jarić, Radović, 2010, 143-144; Cvetinčanin Knežević, Lalatović, 2019)².

Preplet jezičko-političke problematike ovog mocionog podrazreda i njegovog odgovarajućeg imenovanja nameće potrebu ispitivanja novije upotrebe pojmova i određivanja njihove preciznosti, podesnosti

${ }^{1}$ Teorijsko polazište uspostavila je američka lingvistkinja Robin Lejkof 70-ih godina 20. veka, razotkrivajući ideologizaciju značenja i upotrebe engleskog jezika koja reflektuje nejednake odnose među polovima (v. i novije preglede o razvoju i uticaju anglosaksonskih teorija o odnosu jezika i roda u Srbiji: Filipović, 2011, 409-425; Stevanović, 2019, 64-69).

${ }^{2}$ U jednoj debati Svenka Savić je napomenula: „Nažalost, mediji su svoje uključenje $\mathrm{u}$ ovu aktuelnu temu manifestovali «borbom» za i protiv rodne ravnopravnosti u jeziku, a da pri tom najčešće izostavljaju jasnu edukativnu dimenziju o tome o čemu se zapravo radi” (Savić, 2010, 126). 
i razumljivosti. U ovom radu ne koristim pojam ,rodno osetljiv jezik” jer je mnogo širi od imenica za označavanje društvenog statusa, funkcije ili profesije žena. Zbog podudarnosti značenja sa ,imenicama koje označavaju društveni status, funkciju ili profesiju žena" i zbog kratkoće izraza upotrebljavam normativnu pozajmljenicu ,socijalni femininativi”. Za udžbeničku tekstoteku (gramatike i priručnike srpskog jezika) osnovnog i srednjeg obrazovanja, za medije i šire čitalaštvo smatram da je razumljiviji i prikladniji domaći naziv - ,imenice za označavanje društvenog statusa, funkcije ili profesije žena".

Prva naučna monografija o mocionim sufiksima u srpskohrvatskom jeziku nastala je na osnovu odbranjene doktorske disertacije Bože Ćorića, koja je u skraćenom obliku objavljena 1982. godine i u kojoj je dat iscrpan pregled prethodnih istraživanja ove teme. Osamdesetih godina 20. veka i domaći i inostrani lingvisti primećuju da se potiskuju ,ženske” pluralske kongruencije u korist „muških” (Ивић, 1989, 35) і upozorava se na „tendenciju maskulinizacije” u srpskohrvatskom jeziku (Savić, 1995). Preokupacije naučnih analiza bile su strukturalističke, sociolingvističke, feminističke, odnedavno i leksikografske (detaljnije o leksikografskim uvidima v. Matas Ivanković, 2006; Štasni, Mitro, 2009; Mihaljević, Štebih Golub, 2009; Ристић, 2019).

Tokom ispitivanja socijalnih femininativa mogu da se uoče dva sukobljena mišljenja: normativista srpskog (ranije srpskohrvatskog) jezika sa jedne strane, a sa druge sociolingvista i feminističkih lingvistkinja. Ispostavilo se da u novijim predstavljanjima ove teme postoje ozbiljni metodološki propusti koji su u vezi sa antiepistemologijom, koja se po definiciji odnosi na skrivanje i iskrivljavanje znanja. Cilj ovog rada je da ukaže na antiepistemološke probleme i skrene pažnju na širenje i učvršćivanje netačnih tvrdnji i neadekvatnih tumačenja. Usredsrediću se na analizu metodoloških problema u novijim radovima srpskih lingvista i lingvistkinja i predstaviću neke primere ranijih proučavalaca srpskohrvatskog jezika.

Radi razumevanja znanja o socijalnim femininativima nastojalo se odgovoriti na sledeću grupu pitanja. Kakva je metodologija naučnih znanja o socijalnim femininativima? Kako su formulisani naučni problemi? Da li se i kako prikazuje relevantna literatura? Postoji li sistematizovan pregled primarnih, sekudarnih i tercijarnih izvora? Da li su tvrdnje potkrepljene pouzdanim izvorima i adekvatnim argumentima? Da li su uvaženi 
drugačiji pogledi na istu temu i da li se na njih adekvatno odgovorilo? Kakvi su dokazi predstavljeni? Postoji li razlika između pouzdanosti institucionalizovanog i neinstitucionalizovanog javnog znanja o socijalnim femininativima? Kakva je etika istraživanja?

\section{Novi pojmovi, teorijski okviri, metode, razmotreni izvori}

Suprotno epistemologiji, koja je definisana kao proces otkrivanja i čuvanja znanja, antiepistemologija podrazumeva sakrivanje i iskrivljavanje znanja. Termin antiepistemologija (engl. antiepistemology) nedavno je sugerisao Piter Galison (2004, 229-243), poentirajući blokiranje prenosa znanja i posledice tog blokiranja na demokratiju. Uočen raskorak između onoga što neki autori pišu u jezičkim priručnicima koji se koriste kao udžbenička tekstoteka i onoga što izjavljuju za medije može se dovesti u vezu sa ,preferiranjem falsifikata” (engl. preference falsification) ili fenomenom koji je u skorije vreme elaborirao Timur Kuran. To je svako „netačno i lažno predstavljanje nečijih želja zbog društvenog pritiska" (Kuran, 1997, ix [prev. S.T.]); ima za cilj manipulaciju percepcijama drugih o motivacijama ili narativima neke javne ličnosti; ostavlja velike posledice na društvo jer, osim što se ,živi laž”, proizvodi neefikasnost, hrani neznanje i zbrku, skrivajući društvene mogućnosti.

$\mathrm{U}$ ovom radu koristim termin institucionalizovano javno znanje (engl. institutionalized public knowledge) prema značenju Lorejn Koud (Code, 1995, 175); to je znanje koje su uspostavljali muškarci kao privilegovana društvena grupa koja svoj autoritet i ekspertizu nije uvek legitimisala kroz poštovanje naučnih standarda, već čuvanjem/održanjem asimetričnih, nejednakih društvenih i institucionalnih odnosa. Koud je naglasila potrebu kritičkog proučavanja pouzdanosti, istinitosti i objektivnosti institucionalizovanog javnog znanja ,zato što se češće potvrđuje da je autoritet ovih muškaraca uspostavljen pomoću institucionalne moći a ne pomoću dobro argumentovanih analiza, koje jedino mogu da opravdaju poverenje u ekspertizu nečijeg znanja" (Tomić, 2014, 36).

Iako u poslednjih nekoliko decenija raste broj naučnih radova univerzitetskih profesorki koje na nekim fakultetima i centrima za ženske studije u Novom Sadu i Beogradu prenose znanja iz feminističke lingvistike, 
rezultati njihovih istraživanja nedovoljno su uzimani u obzir od strane normativista. U udžbeničkoj tekstoteci i ključnim priručnicima ti rezultati su ignorisani, nisu u dovoljnoj meri prisutni u formalnom obrazovnom sistemu, vidljiviji su u štampanim medijima i onlajn publikacijama. Znanje ovih univerzitetskih profesorki i istraživačica zato je adekvatnije definisati kao ,javno znanje”. Videćemo kasnije u radu da li je ovo svojevrsno odbacivanje od strane normativista argumentovano valjanim dokazima i kakva je naučna etika ovog negiranja.

$\mathrm{Za}$ analizu razumevanja socijalnih femininativa korištene su opšta metodologija (logika) i metodologija naučnog istraživanja (Ilić, 1996; Booth, Colomb Williams, 2008). Razmatrani su sledeći izvori: tekstoteka normativista srpskog jezika (pravopis, gramatika, rečnik srpskog i srpskohrvatskog jezika: Daničić, 1864; Пешикан, Јерковић, Пижурица, 2010; Пипер, Клајн, 2013; Речник, 1967-1976; Речник, 2011); naučne studije i članci u srpskoj (Ивић, 1989, 27-44; Ћорић, 2008, 202-209; Пипер, 2014, 149-159; 2016, 35-65; Драгићевић, Утвић, 2019, 187-200), srpskohrvatskoj (Matić, 1938, 167-168; Vince, 1954, 113-118; Ћорић, 1982; Barić, 1987, 85-88; Kramarić, 1987, 120-125; Ćorić, 1990, 103-108; Savić, 1995) i hrvatskoj lingvistici (Babić, 2006, 81-87; Pišković, 2018; Baraban, Jozić, 2019, 1-26), i tekstoteka srpskih sociolingvista i feminističkih lingvistkinja (naučne monografije, tematski zbornici, rečnici i priručnici, naučni članci: Срдић-Поповић, 1913, 115-125; Savić, 1995; Bugarski, 2005, 53-66; Perović, 2008, 119-138; Rosić, 2008, 11-27; Savić, 2009; Gvozdanović, 2010, 225-229; Filipović, 2011, 409-425; Stošić, 2016; Игњатовић, 2018; Savić, Stevanović, 2019; Stevanović, 2019, 6481; Stefanović, Glamočak, 2019; Cvetinčanin, Lalatović, 2019; Bašaragin, 2020). Takođe su uzimani u obzir master radovi i doktorske disertacije koji se tiču ovog pitanja (Бошковић, 2015; Stevanović, 2017; Ristić, 2019), dokumenta Vlade Republike Srbije (2016) i Zaštitnika građana RS (2010), kao i novinski članci iz novijeg vremena (Пипер, 2009; Stevanović, 2012; Stevanović, 2014a; Stevanović, 2014b; Nikolić, Trikoš, 2016; Клајн, 2017; 2018; Mićević, 2017; Nikoletić, 2017; Ristović, Tulimirović, 2017; Petrović, 2019). Korištene su i antologije srednjovekovnih tekstova, album slavnih novovekovnih žena i istoriografske monografije (Маринковић, 1996; Српкиња, 1913; Веселиновић, 1909; Томин, 2007; Popović, 2014; Станков, 2011). 


\section{Rezultati istraživanja}

U analizi epistemologije novijih radova o socijalnim femininativima otkriven je niz problema. Zbog ograničenog obima ovog rada, najpre ću izdvojiti probleme, potom predstaviti dokaze, i na kraju skrenuti pažnju na dodatna pitanja.

Obe struje ne prenose utvrđene činjenice iz istorijskih istraživanja o tome koliko je stara upotreba mocionih sufiksa.

Jedan od kodifikatora srpske gramatike, Predrag Piper, neodređeno navodi da socijalni femininativi „postoje odavno” (Пипер, 2016, 37). Rajna Dragićević i Miloš M. Utvić pozivaju se na Piperov rad te ponavljaju da je proces širenja socijalnih femininativa „odavno uočen” (Драгићевић, Утвић, 2019, 189). U najnovijim jezičkim priručnicima feminističke lingvistkinje takođe ne pominju istoriju postojanja mocionih sufiksa (Savić, Stevanović, 2019; Cvetinčanin Knežević, Lalatović, 2019). Kako je odmah na početku svoje studije naglasio Božo Ćorić (Ћорић, 1982, 19), mocioni sufiksi vode poreklo iz praslovenskog jezika. To znači da su ovakvi derivati ulazili u jezik još od starog veka i da su tokom daljih vekova proširivali leksiku, što je Ćorić, i dokazao pomoću brojnih primera, koristeći rečničku građu i komentarišući upotrebu u narodnom govoru.

U vezi sa tim problemom je pitanje kako se remetio, umanjivao i oduzimao mentalni leksikon (leksička memorija) ovih sufiksalnih imeničkih izvedenica ženskog roda. Dodatni problemi uočavaju se sa sledećim promenama. Početkom 21. veka feminističke lingvistkinje uvode termin „rodno osetljiv jezik" nastojeći da podrže vidjivost i ravnopravnost žena u društvu. Ovaj termin se potom prihvata i prenosi u službena dokumenta (Заштитник грађана PC, 2010), ali i u dokumenta koja se tiču političke strategije Vlade Republike Srbije (2016). Već u to vreme, u mejnstrim ali i onlajn medijima može da se primeti snažna osuda i omalovažavanje radova feminističkih lingvistkinja, koju je pratilo nerazumevanje i karikiranje socijalnih femininativa ${ }^{3}$. Jednu grupu primera ovakvih neprikladnih reči izdvojila je Marjana Stevanović

${ }^{3}$ „Mejnstrim mediji” (mainstream media) označavaju tradicionalna sredstva javnog informisanja (dnevni i nedeljni listovi, TV, radio) i odražavaju prevladavajuća mišljenja, uticaje i aktivnosti. „Onlajn mediji” (online media) odnose se na širenje vesti putem korišćenja interneta i društvenih mreža, uključuju veb-sajtove tradicionalnih medija, blogove, Facebook, Google, Twitter, YouTube itd. 
u novinskom članku iz 2018. godine, nastojeći da ukaže i na problem degradiranja stručnosti feminističkih naučnica (Stevanović, 2018). Ova neprimerena retorika zaslužuje posebnu istraživačku pažnju, jer se izgleda najpre pojavila i prihvatala u naučnim radovima, a potom prenosila u medije. Kada pišu o nekim primerima socijalnih femininativa u štampi, koji svedoče o prodoru ovih oblika u medije, Dragićević i Utvić, poput Pipera, koriste sintagmu „nasilje nad jezikom” (Пипер, 2009; Драгићевић, Утвић 2019, 197), „,nasilno nametanje novih reči” (Драгићевић, Утвић, 2019, 189) „nasilno tvoreni movirani femininumi” (Драгићевић, Утвић, 2019, 197). Novije pokušaje feminizacije jezika Piper definiše kao „opasan [...] ideološki inženjering u gramatici” (Пипер, 2016, 58), a to mišljenje citiraju kasnije Dragićević i Utvić (2019, 189). Postoje i slučajevi kada se neka imenovanja naučnica mogu razumeti kao omalovažavanja: ,specijalistice za gendernu problematiku” (Пипер, 2009), premda je reč o univerzitetskim profesorkama, od kojih su neke, poput Svenke Savić, zbog posebnih priznanja i zasluga u nauci dobile titulu emerite.

Ako je podnaslov u dnevnom listu Blic u 2017. godini stavio znak jednakosti između feminističkih lingvistkinja i „silovanja jezika” (Ristović, Tulimirović, 2017), novinski naslov na veb-sajtu državnog servisa RTS-a imenovao ih je u 2019. kao „dželatkinje srpskog pravopisa” (Petrović, 2019). Treba detaljnije ispitati veze između političkog zaokreta Vlade Republike Srbije, medijskog gradiranja negativnog odnosa prema socijalnim femininativima i moći delovanja mišljenja Pipera, koji u svojim novinskim tekstovima i naučnim radovima tvrdi da se radi o "silovanju jezika” i zahtevima ,političke korektnosti” (Пипер, 2009), uticaju „globalnog pokreta koji se u sociologiji naziva radikalnim feminizmom" (Пипер, 2016, 36) ili svojevrsnom ,ideološkom inženjeringu u gramatici” (Пипер, 2016, $58)^{4}$. Novija istraživanja pokazuju da mejnstrim mediji, uprkos proboju

${ }^{4}$ Zanimljivo je da se u potkrepljivanju svoje tvrdnje Piper poziva na politikologa i sociologa, univerzitetskog profesora Slobodana Antonića i njegovu knjigu Iskušenja radikalnog feminizma (2011), dok je u nekim ranijim tekstovima Piper zastupao izričit stav da lingvističkim pitanjima treba da se bave samo lingvisti (Пипер, 2009). Dodatno, treba primetiti da Piper pogrešno imenuje i pogrešno tumači (a posebno je pitanje da li pogrešno i razume) neke pojave. On u naučnom radu upozorava javnost na radikalni feminizam, ali ne objašnjava šta pod tim pojmom, koji je inače sporan i izvan i unutar feminizma (Zaharijević, 2011, 139), podrazumeva, a nastoji da sugeriše javnosti pogubno dejstvo te feminističke struje (Пипер, 2016, 36, 48). Osim toga, feminističke lingvistkinje u Srbiji ne pripadaju radikalnim feministkinjama. Svenka Savić i saradnice ni radovima iz prethodnih decenija, pa ni u najnovijem 
novih onlajn medija, imaju ključnu ulogu u oblikovanju javnog mnjenja na društvenim mrežama (Fejsbuku, Tviteru, blogovima) (Newman, 2009). Treba postaviti i pitanje odgovornosti naučnika i medija, i tražiti javno pojašnjenje i ispravke. Takođe, treba ispitati slične reakcije iz prošlosti i ustanoviti da li postoji njihova veza sa intenzivnijim probojem žena u nove sfere javnog delovanja. Na primer, da li je slučajna ista negativna reakcija nastala povodom sve češće upotrebe imenice predsednica posle izbora Milke Planinc za predsednicu SIV-a SFRJ? Da li je tadašnji izbor retoričkog napada Ivice Kramarića postao model za kasnije naučne i medijske napade?

Normativisti ističu da je muški rod u srpskom jeziku generički i neutralan, ne prenose otkrića psiholingvističkih i feminističkih lingvističkih istraživanja koja poriču neutralnost muškog roda.

U glavnom normativnom priručniku (Пипер, Клајн, 2013) ne prenose se otkrića psiholingvističkih i feminističkih lingvističkih istraživanja. Ranije je upozoreno: „Nazivi u muškom rodu nisu neutralni i ne ukazuju na oba spola u istoj mjeri" (Gvozdanović, 2010, 227) ${ }^{5}$. Dok feminističke lingvistkinje sve brojnijim publikacijama nastoje da pomoću uvećanja leksike socijanih femininativa učine žene vidljivijim u javnoj sferi, stiče se utisak da normativisti imaju suprotne namere.

Sa druge strane, u najnovijim jezičkim priručnicima feminističke lingvistkinje ne unose normativističku literaturu (Savić, Stevanović, 2019) ili je redukuju (Cvetinčanin Knežević, Lalatović, 2019), a ispušteni su iz vida raniji kritički uvidi. Na primer, upotrebnu vrednost i značenje reči spisateljica treba ponovo razmotriti uzimajući u obzir kritičke komentare sociolingvista (Bugarski, 2005, 62) i feminističkih lingvistkinja i teoretičarki književnosti (Perović, 2008, 119-138; Rosić, 2008, 11-27).

Obe struje slabo obaveštavaju o tome da su socijalni femininativi potpomogli političko promovisanje žena i razvijanje sociopolitičke leksike i terminologije.

vodiču ne traže revoluciju, već dijalog, „dogovaranje i razgovaranje” (Savić, Stevanović, $2019,15)$, što su reči koje veoma često upotrebljavaju.

${ }^{5}$ Gvozdanović navodi rezultate psiholingvističkih istraživanja Lize Irmen i Nadje Rosberg sa Univerziteta u Hajdelergu iz 2004. godine, ,koje su pokazale da pri spominjanju zanimanja u muškom rodu većina ljudi u prvom redu misli na muškarce, pa tek onda na ženu" (Gvozdanović, 2010, 227). 
Socijalni femininativi su pomogli političko promovisanje moćnih žena (vladarki i rukovoditeljki institucija), ali i „novih žena” (new women) ili žena sa profesijom, bogateći sociopolitičku leksiku i terminologiju (više informacija o terminu „nove žene” i njegovom složenom značenju v. Petterson, 2008, 1-26). U kontekstu ove teme, to znači da upravo socijalni femininativi pokazuju da su žene tokom istorije civilizacije imale različite sociopolitičke uloge, ali i moć, koja ih je jezički obeležavala. Za istoriju jezika i književnosti, kulture i politike, istoriju društva i sociologiju rada bilo bi dragoceno ispitati u kojoj su meri žene same izgrađivale ovakvu leksiku. Žene su kao novi, individualizovani, sociološki i politički subjekti postale jezički označene, a ta političko-jezička svest o novom subjektu prenosila se ili blokirala govorniku u jezičkoj zajednici.

Socijalni femininativi su deo jezika kojim se prihvata i pokazuje društveno-politička uloga žena u razvoju društva. Oni takođe pomažu da se prati poboljšanje ili pogoršanje položaja žena u društvu, ili „kako se u jeziku reflektuje društveni položaj ženskog dela čovečanstva" (Ивић, 1989, 36). Za feminističke lingvistkinje ,jezička vidljivost žena u javnoj sferi, koju u srpskom jeziku u dobroj meri obezbeđuje upotreba zanimanja i titula u gramatičkom ženskom rodu, najvidljivije dekonstruiše patrijarhalne kulturne obrasce" (Savić, Stevanović, 2019, 22).

\section{U nekim radovima, savremeni normativisti odvajaju veze jezika,} društva i politike.

Kod nekih savremenih normativista, npr. Predraga Pipera, nalazi se tvrdnja koja se može oceniti kao sporna, da „pitanje izgradnje femininativnih neologizama ne pripada toliko lingvistici, već sociologiji i politici" (Пипер, 2014, 147; v. i Пипер, Клајн, 2013, 54-56). Jezik stvaraju i koriste ljudi, nije nezavisan od društva i politike. Promene u društvu i politici odražavaju se i u jeziku. Nauka o jeziku treba da reaguje na promene u društvu, a ne da ih ignoriše. Važnu specifičnost socijalnih femininativa objasnili su npr. Božo Ćorić u svojoj monografiji iz 1982. i Milka Ivić u svom članku iz 1989. godine. Ćorić je odmah u uvodu svoje monografije skrenuo pažnju da je „imenička mocija kao tvorbena kategorija pod snažnim dejstvom ekstralingvističkog faktora [kurziv S.T.]" (Ћорић, 1982, 14). Odmah je potom Ćorić napomenuo da su upravo socijalni femininativi ulazili u jezik zbog poboljšanja položaja žena u društvu. Ekstralingvistički faktori odražavaju vezu jezika, kulture i vremena, osvetljavaju 
izmenjene kulturološke uslove, poentiraju promenu jezika zbog društvenih okolnosti, zbog čega otvaraju istraživačko polje i uvećavaju mogućnost ukrštanja različitih disciplina.

Dok je u drugoj polovini 20. veka standardizacija sociopolitičke leksike i terminologije bila blokirana, kasnije je ostvarena u Sloveniji, Hrvatskoj i Crnoj Gori. Vlada RS je takođe 2016. godine usvojila Nacionalnu strategiju za rodnu ravnopravnost za period od 2016. do 2020. godine, u kojoj je skrenuta pažnja da se do 2015. godine nije realizovala preporuka da se standardizuje ,rodno osetljiv jezik”. U najnovijem jezičkom priručniku podseća se da je Srbija potpisala međunarodne ugovore i dokumenta (UN, EU) i ,obavezala se da će primenjivati postojeće standarde u oblasti rodne ravnopravnosti” (Misija OEBS-a u Srbiji, 2019, 5).

Normativisti netačno prikazuju upotrebu socijalnih femininativa, tvrdeći da se te imenice, ,izbegavaju u naučnom i administrativnom stilu" (Пипер, Клајн, 2013, 55).

Socijalni femininativi se više decenija upotrebljavaju u različitim vrstama naučnih radova, od onih manjeg obima poput članaka u naučnim časopisima, do doktorskih disertacija, naučnih monografija i rečnika (v. reference nastale u vremenskom rasponu 1909-2020) ${ }^{6}$. Ove imenice se upotrebljavaju i u administrativnom stilu, a u nekim službenim spisima nalaze se i preporuke za njihovu upotrebu (Заштитник грађана PC, 2010; Влада Републике Србије, 2016).

Neki normativisti netačno tvrde da u drugoj polovini 20. veka nije bilo „nepotrebne politizacije” ove jezičke teme (Пипер, 2016, 38).

U dva nedavno objavljena članka Piper tvrdi da se u drugoj polovini 20. veka ,ni u jednom od radova nije ponudila ideja niti branila potreba uvođenja potpune gramatičke simetrije" (Пипер, 2014, 147) te da u tom periodu nije bilo „nepotrebne politizacije” ove jezičke teme (Пипер, 2016, 38). U oba članka Piper se poziva na niz naučnika, a upravo je prvi kojeg je pomenuo (Vince, 1954, 113-118) smatrao sasvim suprotno. Pitanje socijalnih femininativa Zlatko Vince je 1954. godine video kao veoma potrebno političko pitanje koje naše vlasti moraju da reše jezičkom

\footnotetext{
${ }^{6} \mathrm{Na}$ primer, primena socijalnih femininativa može da se prati u naučnom časopisu Genero, koji je kategorizovan od strane Ministarstva prosvete, nauke i tehnološkog razvoja Republike Srbije. Izlazi od 2002. godine kao nastavak časopisa Ženske studije (1995-2002).
} 
standardizacijom, jer su takve imeničke izvedenice (socijalni femininativi) ne samo u duhu jezika već i deo društvene stvarnosti koja ukazuje na unapređenje položaja žena. Zbog ovog metodološkog propusta nađenog u Piperovim člancima treba temeljno proveriti radove svih drugih autora koje je Piper naveo i utvrditi u kojoj meri potkrepljuju Piperovu tvrdnju. Osim toga, treba utvrditi šta se tačno misli pod ,politizacijom”, da li se to pitanje i ranije pokretalo i sa kakvim obrazloženjima ${ }^{7}$.

U vezi sa prethodnim problemom je slabo proveravanje tačnosti tvrdnji normativista i izvora koji su korišteni kao dokaz; neki tekstovi se netačno tumače ili ignorišu.

Ne proveravajući tvrdnje autoriteta, Dragićević i Utvić prenose njihovu netačnost: „o tome su pisali, «bez nepotrebne politizacije» brojni istraživači. P. Piper navodi da je Z. Vince pisao o tome još davne 1954. godine" (Драгићевић, Утвић, 2019, 189). Tokom rasprava kod obe se struje primećuje netačno tumačenje pojedinih autora i autorki. Na primer, prilikom razmatranja nekih socijalnih femininativa, Dragićević i Utvić se pozivaju na rad Bože Ćorića, te skreću pažnju na činjenicu da je autor takve konstrukcije ocenio kao one sa ,prilično rogobatnom fonološkom strukturom” (Драгићевић, Утвић, 2019, 192). Ali, kada se vratimo na Ćorićev tekst, uviđamo da ovaj naučnik nije tako opisao neke primere, već je skrenuo pažnju na „teško izgovorljivu konsonantsku skupinu” (Һорић, 2008, 206). Kod Dragićević i Utvić reč je o deskriptivnoj tvrdnji koja se meša sa analitičkim tvrdnjama; ovakvu je mešavinu Teri Iglton (Eagleton, 2007, 49) definisao kao ideološku.

Primećuju se netačna tumačenja i sa druge strane. Eugenija Barić je netačno inerpretirala Božu Ćorića, a pažnju na to je skrenula Milka Ivić napominjući da Ćorićev rad ,ne daje pravog povoda za tvrdnju da se on postavlja kao protivnik «ženskih» imenica” (Ивић, 1989, 42, fusnota br. 38). Osim toga, Milka Ivić ukazuje na Ćorićeve dragocene primedbe o većoj upotrebnoj rasprostranjenosti socijalnih maskulinativa iako postoje socijalni femininativi, te naglasila da vladaju česta kolebanja u korišćenju socijalnih femininativa. M. Ivić je smatrala da su socijalni femininativi

${ }^{7}$ Reč „,politizacija” ima različita značenja. Šire značenje se odnosi na premeštanje moći regulisanja neke teme i/ili debatiranja o nekoj temi u političkoj sferi. U srpskom javnom diskursu i stručnoj literaturi primećena je sklonost ka uskom i negativnom značenju; to je reč kojom se opisuje upliv politike tamo gde ne bi trebalo da to bude slučaj (detaljnije o pojmu i upotrebi v. Radić Milosavljević, 2018, 19-23). 
opravdani i potrebni, no to su, izgleda, normativisti prećutkivali u svojim radovima. M. Ivić je iskazala i verovanje da će te imenice ući u standardizovanu leksiku sa većim prodorom žena u javnu sferu društva. Zanimljivo je da je pomenuta naučnica predviđala da neće „feministički”, već gramatički, tj. „kongruencijski razlozi” (Ивић, 1989, 42), uticati na normativističko prihvatanje socijalnih femininativa. To se pak do danas nije desilo. Piper odbacuje tu mogućnost, tvrdeći da ,lingvističke argumentacije [...] u pravom smislu reči tu ni nema" (Пипер, 2009).

U radovima normativista retko se obaveštava o tome da već nekoliko decenija postoje empirijske analize jezika medija, ponegde i udžbenika.

Pregled empirijskih istraživanja dala je Svenka Savić (1995) omogućivši uvid u stanje stvari iz 50-ih i 60-ih godina 20. veka, pokazujući da maskulinizacija nije toliko u vezi sa društvenom praksom već sa sistemom jezika, te da postoje kolebanja u upotrebi forme za zanimanje žena. Ovoj grupi istraživanja treba pridodati i Ćorićevu analizu ženske revijalne štampe, radio i TV emisija sa kraja 80-ih godina 20. veka iz Beograda, Sarajeva i Zagreba (Ćorić, 1990, 103-108). Ćorić je tom prilikom izdvojio leksičke inovacije, naveo reči kojih nije bilo u Matičinom šestotomnom rečniku (čime je nadopunio svoje istraživanje iz 1982. godine) i ukazao na lektorske intervencije i uredničku politiku, što je pitanje na koje će u novije vreme skrenuti pažnju Marjana Stevanović (2017; 2019).

U glavnim jezičkim priručnicima normativista retko se pominju kontroverze iako one postoje kod obe struje i to povodom različitih pitanja.

Obično se kontroverze razmatraju u naučnim radovima i polemikama. U novije vreme uviđa se potreba za potpunijim predstavljanjem znanja o nekoj temi i u udžbeničkoj tekstoteci. Pregled kontroverzi sa početka 21. veka koje se tiču standardizacije rodno osetljivog srpskog jezika predstavila je M. Stevanović (2017) u svom master radu, čiji je deo sažeto objavljen kasnije (Stevanović, 2019, 67-69). Osim sukoba među normativistima u vezi sa zvaničnim prihvatanjem socijalnih femininativa (Stevanović, 2017, 22; Nikoletić, 2017), primećuju se radovi hrvatskih lingvista u kojima se dotiče problematika političkog otpora i konzervativnosti srpskih lingvista (Babić, 2006, 86) ${ }^{8}$. Ilustrativne

${ }^{8}$,Zanimljivo je ovdje napomenuti da Srbi tek ove godine raspravljaju o zakonu o ravnopravnosti spolova i pri tome spominju i jezičnu ravnopravnost, ali u jezičnome pogledu ne 
primere institucionalnih kontroverzi iz novijeg vremena dale su S. Savić i M. Stevanović $(2019,19)$. Uočava se i izvesna nepodudarnost između pozitivnog stava Klajna prema socijalnim femininativima u štampi i negativnog u Normativnoj gramatici ${ }^{9}$. Zbog toga se može postaviti sledeće pitanje. Ako Klajn pripada suprotnoj struji, zašto prilikom objavljivanja Normativne gramatike 2013. godine nije pokazao drugačiji stav prema upotrebi socijalnih femininativa? Posebno je pitanje da li je ta specifična dvostrukost rezultat tradicionalnog pristupa u obradi građe ili je ona u vezi sa ,preferiranjem falsifikata” (Kuran, 1997), odnosno sa netačnim predstavljanjem vlastitih želja zbog medijskog i političkog pritiska o potrebi korišćenja socijalnih femininativa ${ }^{10}$.

Kontroverze, nerešene probleme i neslaganja među naučnicima treba temeljno ispitati posebno zbog toga što doprinose razumevanju nauke i njene prirode. $U$ jednom novijem istraživanju zaključeno je da upravo zbog takve svoje odlike kontroverze treba da budu uključene u nastavne programe (Dunlop, Veneu, 2019, 689-710). Jedno od važnih pitanja je kada je tačno došlo do neslaganja u vezi s upotrebom i standardizacijom socijalnih femininativa. Sam istorijat sporova nije detaljno ispitan, a kod obe struje izostao je potpuniji uvid u bibliografiju radova. Svenka Savić (1995) npr. pominje rad Janjanina iz 1934. godine, ali ne navodi Matića iz 1938. godine. U medijima se mogu naći tekstovi u kojima se tvrdi da su se sporovi zahuktali od 2001. ${ }^{11}$ ili 2009. godine sa knjigom S. Savić. Tom prillikom Klajn pogrešno obaveštava javnost da se pre 2009. godine „niko time nije pozabavio” (Klajn, prema Stevanović, 2014b).

kane ništa mijenjati jer istaknuti jezikoslovci misle da se ne može ništa mijenjati u sustavu kako ga je opisao Ivan Klajn" (Babić, 2006, 86, fusnota br. 12).

9 ,Jezik je konzervativan, inertan, teško menja svoje navike, pa se i ovde postepeno, bez «nasilja nad rečnikom», moramo truditi da rodna ravnopravnost koja se sve više ostvaruje u društvu dobije i odgovarajući jezički odraz" (Klajn, prema Nikoletić, 2017). V. i druge primere Klajnovih izjava za štampu kod Stevanović, 2017 i 2019. U Normativnoj gramatici socijalni femininativi novijeg porekla ne vide se kao „odlika dobrog književnog jezika” (Пипер, Клајн, 2013, 55).

${ }^{10}$ Ovde će biti korisne za razmatranje i Klajnove kolumne o socijalnim femininativima objavljene u NIN-u (v. npr. novije tekstove: Клајн, 2020 і Клајн, 2021).

${ }^{11}$ „Počev od 2001. godine u javnosti zahuktali sporovi oko insistiranja jedne grupe «borkinja» za ženska prava da se u sferi jezika intenzivira stvaranje i upotreba imeničkih reči za označavanje ženskih nosilaca zanimanja, funkcija, zvanja i sl.” (Terzić, 2006). 


\section{Razmotrena dijahronijska istraživanja socijalnih femininativa} u srpskohrvatskom, srpskom i hrvatskom jeziku retko su uzimala u obzir dokumenta vladarki, dela književnica iz prošlosti, kao i istoriografske monografije.

Prethodna istraživanja (Ћорић, 1982; Ćorić, 1990; Matas Ivanković, 2006; Štasni, Mitro, 2009) nesumnjivo su donela važne uvide iz istorijske lingvistike. Dalja analiza može da se usredsredi na izvore koji mogu da pomognu utvrđivanje činjenica o odnosu moćnih i novih žena prema jeziku, da li su koristile socijalne maskulinative ili socijalne femininative, da li su $\mathrm{u}$ ispisivanju svojih subjektiviteta vršile izvesna samoodređivanja. Takođe je važno ispitati šta je uticalo na slabo saznavanje činjenica o tome kako su u prošlosti statusno drugačije žene (npr. vladarke i supruge vladara) bile imenovane i samoimenovane.

Ispostavilo se da istraživanje nekih slabo korišćenih izvora koriguje rezultate prethodnih analiza i postavlja nove probleme. Pisane tragove prvih socijalnih femininativa Ćorić je našao u 12. veku (opatica, gospođa/gospoža), potom u 13. (kraljica) i 14. veku (kneginja, kaluđerica, monahnja). Drugi naučnik, Milojko Veselinović (Веселиновић, 1909, 173-175) naveo je pisane tragove o kaluđericama iz 11. veka, a o monahinjama iz 13. veka. Osim toga, Veselinović je skrenuo javnosti pažnju da su se kaluđerice javljale početkom 4. veka zajedno sa pojavom kaluđera, te da je ustanova kaluđerica bila veoma raširena u drugoj polovini 12. veka (Веселиновић, 1909, 175). Dodao je da je crkveni red đakonica postojao od početka hrišćanstva do 8 . veka, odnosno do 12. veka, kada je sasvim iščezao (Веселиновић, 1909, 162). Treba istražiti da li su u međuvremenu otkriveni neki pisani izvori za đakonice, možda i drugi, raniji izvori za kaluđerice.

Problem nesačuvanih pisanih izvora treba uzeti u obzir kada se utvrđuju istorijske činjenice o ženama i njihovom društvenom statusu, funkciji i profesiji, ali i kada se u novije vreme opisuju uloge žena i njihov jezički status. Ćorić je 1982. godine podsetio da potvrde za stare mocione sufikse „dolaze kasno" ne zbog lingvističkih razloga nego zbog nesačuvanih spomenika. Za pisane spomenike Ćorić je napomenuo da su ,veoma retki”, „najstariji su tek iz XII veka” (Ћорић, 1982, 162). Mogu se takođe uključiti i posredni dokazi o postojanju nekih imenica za označavanje uloga žena u prošlosti. Da li postoje potvrde u narodnom govoru ili nekim drugim 
pisanim izvorima, ostaje da se istraži. Jedan primer iz skorije prošlosti pokazuje postojanje potvrde u književnom delu sa početka 20. veka za vojnu titulu barjaktar-devojka, pri čemu se upućuje na činjenice iz srpske istorije 19. veka i postojanje različitih narodnih pesama ${ }^{12}$. Dok u Matičinom šestotomnom Rečniku srpskohrvatskoga književnog jezika (I/A-E, 143) postoji samo reč barjaktaruša, u figurativnom značenju 'ženska osoba koja prednjači u čemu, kolovođa'. Rečnik srpskoga jezika iz 2011. sadrži imenicu barjaktarka u značenju 'žena barjaktar', ali posle imenice zastavnik za označavanje najvišeg podoficirskog čina u vojsci ne nudi imenicu zastavnica, koju kao formu ženskog roda predlažu Svenka Savić i Marjana Stevanović (2019, 78; v. Речник, 2011, 60, 400). Treba, dakle, pratiti i razlike između leksema za socijalne femininative tokom razvoja jezika, kao i procese njihove standardizacije i upotrebne varijacije.

Drugi primer proširenog korpusa takođe koriguje Ćorićeva otkrića. Reč je o antologiji autobiografskih tekstova iz srednjeg veka Pisah i potpisah, koju je priredila Radmila Marinković 1996. godine ${ }^{13}$. Uveravamo se da su srpske vladarke koristile socijalne femininative koje Ćorić ne pominje. Na primer, Jelena, žena despota Uglješe Mrnjavčevića, u 14. veku sebe imenuje despotica (Маринковић, 1996, 157). Ćorić navodi da je leksema kraljica postojala u 14. veku, a potvrde postoje i iz 13. veka (Маринковић, 1996, 68). Veoma je neobičan primer iz 14. veka Mare Branković, supruge turskog sultana Murata II, koja je u različitim dokumentima sebe potpisivala kao сагіси (Маринковић, 1996, 167, 169) upravo u vreme kada je udovica i kada se opire ponovnoj udaji, nastojeći da zadrži i sačuva veliki ugled i političku moć (Popović, 2014, 133). Mara Branković je sebe potpisivala i kao samodržicu (Томин, 2007, 121) i gospodaricu oblasti koje je posedovala (Popović, 2014, 153). Takvim rečima su je imenovali i drugi

${ }^{12}$ Vožd Karađorđe Petrović dodelio je ulogu barjaktara svojoj ljubavnici Mariji, koja je bila preobučena u muško odelo. Kada piše o tome književnik Dragutin Ilić ne upotrebljava reč barjaktarka već barjaktar-devojka, dodatno upućujući na stihove „narodnog pesnika” (v. Ilić, 2015, 6; Ilićev Roman kraljice Natalije najpre je objavljen u periodici 1923. godine, a potom kao knjiga 2015. godine).

${ }^{13}$ Zahvaljujem Svetlani Tomin što mi je skrenula pažnju na pomenutu antologiju i poslala uvide u Istoriju Vizantiije Ostrogorskog, gde nalazimo primer vizantijske carice Irine (752-803), tj. prve žene koja je ponela titulu cara. U zakonskim odredbama Irina sebe nije nazivala carica (vasilisa), već je upotrebljavala muški oblik car (vasilevs), ali na novcu kovanom za vreme njene vladavine sebe naziva caricom. 
velikodostojnici, a susrećemo ih i u jednoj povelji na grčkom jeziku (Popović, 2014, 220).

Božo Ćorić beleži imenicu vladalica u 17. veku, a Radmila Marinković putem teksta kraljice Marije Paleologine pokazuje da se Marija imenovala kao vladarka 1355. godine, dakle u 14. veku (Маринковић, 1996, 140).

Proširen korpus izvora pokazuje da neke debate u srpskom jeziku traju više od 100 godina. Album Srpkinja iz 1913. godine uverava nas da su intelektualke u srpskoj kulturi uveliko koristile razne socijalne femininative i da su razmišljale o adekvatnom izboru i upotrebi imenica ženskog roda za označavanje žena koje se aktivno bave različitim književnim žanrovima i prevođenjem (Срдић-Поповић, 1913, 115-125). U pregledu bibliografije jugoslovenskog feminističkog časopisa Ženski pokret za period 1923-1934. nalazimo doslednu i afirmativnu upotrebu socijalnih femininativa ${ }^{14}$.

Osim što upućuju na probleme leksičke memorije, neki primeri pokazuju snažan otpor prema prihvatanju socijalnih femininativa, posebno kada je reč o ženama koje obavljaju visoke institucionalne poslove ili imaju visoke državne pozicije. Za razliku od Predraga Pipera, Milka Ivić je 1989. godine napomenula da su lingvisti proučavali ove reči posebno sa procvatom sociolingvistike, kada se pažnja proširivala sa jezika na vezu jezika, društva i politike. Neki naučnici su u to vreme napominjali da su prepreke za tvorbu socijalnih femininativa „nejezične” prirode (Barić, 1987, 85) te da ,postoje određene »ženske« upotrebne zone koje, zasad bar, ostaju dosledno potpuno neosvojive" (Ивић, 1989, 36).

U naučnim radovima tokom 80 -ih godina 20 . veka primećeno je da su se izvedenice predsednica i sutkinja koristile već od kraja 70-ih godina 20. veka, sve češće u javnoj službi i štampi, i to više u Zagrebu nego u Beogradu, a naročito ,nakon izbora drugarice Milke Planinc na dužnost predsjednika Saveznog izvršnog vijeća" (Kramarić, 1987, 121) ${ }^{15}$. Ovde se može

${ }^{14}$ Zanimljivo je primetiti da naslovi mnogih članaka časopisa Ženski pokret, koji je izlazio od 1920. do 1938. godine, poentiraju nove profesije za žene te koriste sintagmu kojom se spajaju imenica žena i socijalni maskulinativ. Na primer: žena sudac, žene-advokati (1923), žene počasni doktori (1924), žena-profesor anatomije, žena kao istraživač, prva žena skulptor (1925); (navedeno prema bibliografiji Бараћ, 2015, 337-357; v. i Bašaragin, 2020).

${ }^{15}$ Milka Planinc (1924-2010) obavljala je funkciju predsednice SIV-a SFRJ od 1982. do 1986. godine. Upamćena je kao prva žena-premijer u nekoj socijalističkoj državi. 
postaviti pitanje poznavanja ili nepoznavanja, pamćenja ili zaboravljanja činjenice da se pomenuta reč koristila i ranije, u 19. veku. Uvidi koji su predstavljeni kod Kramarića, Ćorića i Stevanović pokazuju diferencijaciju značenja titule predsednice: ta reč se najpre susreće u dokumentima institucija koje su osnivale žene, a potom i u političkoj sferi. Skrećem pažnju na primere Katarine Milovuk, koja je 1875. postala predsednica Beogradskog ženskog društva ${ }^{16}$, Milke Vulović, koja je 1896. godine bila predsednica Odbora crkve Sv. Natalije (Stevanović, 2017, 46-47; 2019, 74), kao i Milke Planinc, koja je u 20. veku bila predsednica SIV-a, tj. najvišeg izvršnog organa SFRJ-a.

\section{Zaključak}

U ovom radu predstavljeni su neki metodološki problemi dve struje savremenih istraživanja socijalnih femininativa u srpskom jeziku, od kojih jednu čine normativisti, a drugu sociolingvisti i feminističke lingvistkinje. U nekim slučajevima znanje je netačno i uključuje nerazumevanje i neadekvatno tumačenje. Normativisti tvrde da se u naučnom i administrativnom stilu socijalni femininativi izbegavaju iako postoje različiti naučni članci i službeni spisi koji koriste i propisuju upotrebu tih imenica. Pomenuta struja ne pominje snažan uticaj ekstralingvističkog faktora na razvoj ovih imenica niti stvaranje sociopolitičke leksike i terminologije, odvaja veze jezika, društva i politike. Relevantni primarni, sekudarni i tercijarni izvori nisu u dovoljnoj meri obrađeni niti sistematizovani. Kod obe struje primećuje se sklonost ka ignorisanju literature koja nudi drugačije, nove i kritičke uvide u probleme. Na taj način se ne uvažavaju rezultati istraživanja, samim tim ni novo znanje, a umanjuje se i stvaralački potencijal istraživačkog neslaganja.

Kod normativista se ne mogu naći adekvatni odgovori na suprotstavljene tvrdnje. U nekim radovima nisu predstavljena relevantna istraživanja, a drugačija mišljenja negde su prenesena na neadekvatan način. Dokazi u nekim slučajevima nisu pouzdani, npr. izričito se tvrdi da nije bilo „politizacije”

${ }^{16}$ Te 1875. godine u „Pravilima Ženskog društva”, objavljenim u Srpskim novinama, nalazimo ovakve imenice i sintagme: upravne članice, predsednica, potpredsednica, blagajnica i delovotkinja (Станков, 2011, 54). 
teme socijalnih femininativa, a prvi izvor koji se navodi kao referenca pobija tu tvrdnju. Prodor socijalnih femininativa u naučnim radovima nekih normativista i medijima obeležava se, kako od strane naučnika i naučnica tako i novinara i novinarki, neprimerenim jezikom. Kod normativista se primećuje i omalovažavanje naučnica koje pripadaju suprotstavljenoj struji.

Iz ovih se razloga normativističko institucionalizovano javno znanje o socijalnim femininativima može opisati kao ono koje nije sasvim u skladu sa metodologijom naučnog rada; zanemaruje i etičke principe istraživanja. Zbog veće moći svoje institucionalizacije ostavlja veće posledice na društvo.

U ovom radu ukazano je na potrebu proširenja istraživačke građe i njenog interdisciplinarnog proučavanja da bi se potpunije predstavio i bolje razumeo istorijat upotrebe socijalnih femininativa, ali i istorijat sukobljenih struja i istorijat razumevanja pitanja standardizacije kao političkog pitanja. Imenice koje označavaju društveni status, funkciju ili profesiju žena sačuvane su u pisanim izvorima iz 11. (kaluđerica) i 12. veka (opatica, gospođa/gospoža), premda istoriografske studije navode da su od pojave hrišćanstva žene imale različit status u crkvenoj hijerahiji (kaluđerica, đakonica). Izrada dijahronijskog rečnika sa uključenim tekstovima politički moćnih žena i književnica pokazala bi potpuniju sliku aktivizacije, produktivnosti i gašenja ovih imenica.

Do danas se leksika socijalnih femininativa proširivala, ali i sužavala, pa će biti dragoceno istraživati dinamiku ovih procesa. Neki predstavljeni primeri u ovom radu pokazuju da su politički moćne žene koristile socijalne femininative u srednjem veku, pa i kasnije, u 19. veku. Ovi slučajevi ranog samoimenovanja mogu se razumeti i kao političko samopromovisanje.

\section{Literatura}

Babić, S. (2006). Hrvatski jezik, zakonodavstvo i ravnopravnost spolova. „Jezik” knj. 53, br. 3, str. 81-87.

Baraban, B., Jozić, Ž. (2019). Časopis Naš jezik u kontekstu hrvatskoga jezikoslovlja prve polovice 20. stoljeća. „Rasprave” 45/1, str. 1-26. https://doi.org/10.31724/ rihjj.45.1.1.

Barić, E. (1987). Kada sudac a kada sutkinja? „Jezik” knj. 35, br. 3, str. 85-88.

Bašaragin, M. (2020). Upotreba rodno osetljivog jezika u feminističkom časopisu Ženski pokret. [Neobjavljeni rad]. 
Booth, W., Colomb, G., Williams, J. (2008). The Craft of Research. Chicago-London: The University of Chicago Press. https://doi.org/10.7208/chicago/9780226062648. 001.0001 .

Bugarski, R. (2005). Pol i rod u jeziku. U: R. Bugarski. Jezik i kultura. Beograd: Biblioteka XX vek, str. 53-66.

Code, L. (1995). What Can She Know: Feminist Theory and the Construction of Knowledge. New York: Cornell University Press.

Cvetinčanin Knežević, H., Lalatović, J. (2019). Priručnik za upotrebu rodno osetljivog jezika. Beograd: Centar za ženske studije.

Ćorić, B. (1990). Sociolingvistički status naziva za osobe ženskog pola u srpskohrvatskom jeziku. „FLUMINENSIA: časopis za filološka istraživanja” knj. 2, br. 1-2, str. $103-108$.

Daničić, Gj. (1864). Oblici srpskoga jezika. Beograd: Državna štamparija. Digitalna biblioteka Matice srpske.

Dunlop, L., Veneu, F. (2019). Controversies in Science. „Science \& Education” br. 28, str. 689-710. https://doi.org/10.1007/s11191-019-00048-y.

Eagleton, T. (2007). Ideology: An Introduction. London-New York: Verso.

Filipović, J. (2011). Rod i jezik. U: Uvod u rodne teorije. Ur. I. Milojević, S. Markov. Novi Sad: Univerzitet u Novom Sadu ACIMSI-Mediterran publishing, str. 409425.

Galison, P. (2004). Removing Knowledge. „Critical Inquiry” 31 (1), str. 229-243. https://doi.org/10.1086/427309.

Gvozdanović, J. (2010). Diskursi o rodnoj ravnopravnosti u jeziku. U: Zbornik u čast Svenke Savič, Diskursi i diskursi. Ur. V. Vasić. Novi Sad: Filozofski fakultet Univerziteta u Novom Sadu, Ženske studije i istraživanja, 225-229.

Ilić, D. (2015). Roman kraljice Natalije, prir. S. Tomić. Beograd: Službeni glasnik.

Ilić, M. (1996). Naučno istraživanje: opšta metodologija. Beograd: Univerzitet: Filološki fakultet.

Jarić, V., Radović, N. (2010). Rečnik rodne ravnopravnosti. Beograd: Henrich Boll Stiftung.

Kramarić, I. (1987). Još jednom o sucu i sutkinji (Stvar ipak nije tako jednostavna). „Jezik” knj. 35, br. 4, str. 120-125.

Kuran, T. (1997). Private Truths, Public Lies: The Social Consequences of Preference Falsification. Cambridge, MA: Harvard University Press. https://doi.org/10.2307/ j.ctvt1sgqt.

Matas Ivanković, I. (2006). Kada su prvi put u hrvatskim rječnicima zabilježene imenice za ženska zanimanja? „Jezik” knj. 53, br. 1, str. 33-35.

Matić, T. (1938). , Gospođa doktor” i , gospođa profesor”. „Hrvatski jezik” str. 167-168. Mićević, I. (2017). Počela jezička borba borkinja i stručnjakinja. „Novosti” 8.10.2017. https://www.novosti.rs/vesti/naslovna/drustvo/aktuelno.290.html:689554-Pocela-jezicka-borba-borkinja-i-strucnjaka. 16.01.2020.

Mihaljević, M., Štebih Golub, B. (2009). Mocijska tvorba u hrvatskom i srpskom. U: Die Unterschiede zwischen dem Bosnischen/Bosniakischen, Kroatischen und Serbischen III, Slawische Sprachkorrelationen. Ed. B. Tošović. Wien: LitVerlag, str. 81-103. 
Misija OEBS-a u Srbiji (2019). Predgovor. U: S. Savić, M. Stevanović. Vodič za upotrebu rodno osetljivog jezika u javnoj upravi Srbije. Beograd: Misija OEBS-a u Srbiji, str. 5-6.

Newman, N. (2009). The rise of social media and its impact on mainstream journalism: A study of how newspapers and broadcasters in the UK and US are responding to a wave of participatory social media, and a historic shift in control towards individual consumers. University of Oxford-Reuters Institute for the Study of Journalism. https://reutersinstitute.politics.ox.ac.uk/sites/default/files/2017-11/The\%20 rise $\% 20$ of $\% 20$ social $\% 20$ media $\% 20$ and $\% 20$ its $\% 20$ impact $\% 20$ on $\% 20$ mainstream\%20journalism.pdf. 16.01.2020.

Nikoletić, D. (2017). Rodna (ne)osetljivost u jeziku medija: Sobarica-svakako, akademkinja - nikako! „Cenzolovka” 31.10.2017. https://www.cenzolovka.rs/mediologija/rodna-neosetljivost-u-jeziku-medija-sobarica-svakako-akademkinja-nikako/. 16.01.2020.

Nikolić, M., Trikoš, J. (2016). Rodno osetljiv jezik u javnoj upotrebi. „Politika” 15.12.2016. http://www.politika.rs/sr/clanak/370021/Kultura/Rodno-osetljiv-jezik-u-javnoj-upotrebi. 16.01.2020.

Perović, S. (2008). Žensko pismo: semantička diskriminacija i diskursna tolerancija. „Zbornik Matice srpske za filologiju i lingvistiku” knj. 51, br. 1-2, str. 119-138.

Petrović, A. (2019). Dželatkinje srpskog pravopisa. Ovoga puta reč-dve o socijalnim femininativima ... „RTS” 10.06.2019. https://www.rts.rs/page/stories/sr/story/2948/ smatracnica/3551306/dzelatkinje-srpskog-pravopisa.html. 16.01.2020.

Petterson, H. M. (2008). Introduction. U: The American New Woman Revisited: A Reader, 1894-1930. Ur. M. H. Patterson. Rutgers University Press, str. 1-26.

Pišković, T. (ur.) (2018). Uvod u rodolektologiju. U: Rodni jezici: Zbornik radova o jeziku, rodu i spolu. Prev. N. E. Camaj. Zagreb: Zagrebačka slavistika škola, str. 7-33.

Popović, M. (2014). Mara Branković: žena između hrišćanskog i islamskog kulturnog kruga u 15. veku. Novi Sad: Akademska knjiga.

Radić Milosavljević, D. I. (2018). Evropska unija u procesu politizacije. [Neobjavljena doktorska disertacija]. Beograd: Fakultet političkih nauka. https://nardus.mpn.gov. rs/bitstream/handle/123456789/10105/Disertacija.pdf. 16.01.2020.

Ristović, A.,Tulimirović, D. (2017). Akademici za Blic o rodno osetljivom jeziku. Da li su atašeica i trgovkinja 'nepotrebno siljenje' ili pozitivna promena? „Blic” 25.09.2017. https:/www.blic.rs/vesti/drustvo/akademici-za-blic-o-rodnoosetljivom-jeziku-da-li-su-ataseica-i-trgovkinja-nepotrebno/0k799r6. 16.1.2020.

Rosić, T. (2008). Žena-pisac: kiborg u srpskoj književnosti? U: Teorije i politike roda. Ur. T. Rosić. Beograd: Institut za književnost i umetnost, str. 1127.

Savić, S. (1995). Jezik i pol: Istraživanja kod nas. „Ženske studije” br. 2/3. https:// www.zenskestudie.edu.rs/izdavastvo/elektronska-izdanja/casopis-zenske-studije/ zenske-studije-br-2-3/261-jezik-i-pol-ii. 16.01.2020.

Savić, S. (2010). Nesporazumi o rodno osetljivom jeziku u Srbiji: teorije i praksa. U: Okrugli sto na temu rodno osetljivih jezičkih politika. Ur. I. Milojević, S. Mar- 
kov. Beograd: Program Ujedinjenih nacija za razvoj (UNDP) Sektor za inkluzivni razvoj, str. 125-133.

Savić, S., Stevanović, M. (2019). Vodič za upotrebu rodno osetljivog jezika u javnoj upravi Srbije. Beograd: Misija OEBS-a u Srbiji.

Savić, S. (2009). Rod i jezik. U: Rod i jezik. Prir. S. Savić, M. Čanak, V. Mitro, G. Štasni.

Novi Sad: Futura publikacije i Ženske studije i istraživanja, str. 5-35.http://www. zenskestudije.org.rs/pdf/knjige/rod_i_jezik.pdf. 1.02. 2021.

Stefanović, J., Glamočak, S. (2019). Priručnik za uvođenje rodne perspektive u nastavu srpskog jezika za prvi ciklus obrazovanja. Beograd: Tim za socijalno uključivanje i smanjenje siromaštva Vlade Republike Srbije.

Stevanović, M. (2012). Može li srpski jezik postati rodno osetljiv jezik. „Danas” 10.02.2012. https://www.danas.rs/nedelja/moze-li-srpski-jezik-postati-rodnoosetljiv-jezik/. 31.01.2020.

Stevanović, M. (2014a). Klajn: Političare ne zanima jezička kultura. „B 92” 13.10.2014. http://www.b92.net/info/intervju/index.php?yyyy=2014\&nav_id=911201). 16.01.2020.

Stevanović, M. (2014b). Nijedno ministarstvo ne zanima jezička politika. „Danas” 13.10.2014. https://www.danas.rs/drustvo/nijedno-ministarstvo-ne-zanima-jezicka-politika/.16.01.2020.

Stevanović, M. (2017). Kontroverze standardizacije rodno osetljivog srpskog jezika. [Neobjavljeni master rad]. Novi Sad: Filozofski fakultet - ACIMSI.

Stevanović, M. (2018). Srpski jezikoslovci uporno degradiraju stručnost feminističkih znanstvenica. „Voxfeminae“ 25.06.2018. https://voxfeminae.net/pravednost/srpskijezikoslovci-uporno-degradiraju-strucnost-feministickih-znanstvenica/. 5.02.2021.

Stevanović, M. (2019). Rodno osetljiv jezik u medijskoj praksi Srbije. „Filolog” knj. X, br. 19 , str. $64-81$.

Stošić, I. (2016). Vodič za promociju i prihvatanje rodno-osetljivog jezika u Srbiji, Kosovu i Albaniji. Vranje: Romski centar za demokratiju.

Terzić, B. (2006). Veštački ženski. „Politika” 5.09.2006.

Tomić, S. (2014). Realizam i stvarnost: nova tumačenja proze srpskog realizma iz rodne perspektive. Beograd: Alfa Univerzitet, Fakultet za strane jezike. https://www. academia.edu/7800874/Realizam_i_stvarnost_nova_tuma\%C4\%8Denja_proze_ srpskog_realizma_iz_rodne_perspektive_www_fsj_edu_rs_fajlovi_Svetlana3 print_pdf. 16.01.2020.

Štasni, G., Mitro, V. (2009). Registar imenovanja žena. U: Rod i jezik. Ur. S. Savić et al. Novi Sad: Futura publikacije i Ženske studije i istraživanja, str. 35-133.

Vince, Z. (1954). Drugarica direktor, gospođa profesor ili drugarica direktorica, gospođa profesorica. „Jezik” knj. 3, br. 4, str. 113-118.

Zaharijević, A. (2011). Radikalni feminizam. U: Uvod u rodne teorije. Ur. I. Milojević, S. Markov. Novi Sad: Univerzitet u Novom Sadu ACIMSI - Mediterran publishing, str. 139-153. 
Антонић, С. (2011). Искушења радикалног феминизма: моћ и границе друштвеног инжењеринга. Београд: Службени гласник.

Бараћ, С. (2015). Феминистичка контрајавност: жанр женског потрета y српској периодици 1920-1941. Београд: Институт за књижевност и уметност.

Бошковић, В. (2015). Дискурзивна средства за изражавање родних идеологија на примеру студентске популације у Србији. [Необјављена докторска дисертација]. Београд: Филолошки факултет. http://nardus.mpn.gov.rs/bitstream/handle/ 123456789/6204/Disertacija4128.pdf?sequence=1\&isAllowed=y. 16.01.2020.

Веселиновић, М. (1909). Српске калуђерице. „Глас српске краљевске академије” књ. LXXX, стр. 154-256.

Влада Републике Србије (2016). Национална стратегија за родну равноправност за период од 2016. до 2020. године. „Службени гласник РС” бр. 4, 22.01.2016. https://www.mgsi.gov.rs/cir/dokumenti/nacionalna-strategija-za-rodnu-ravno pravnost-za-period-od-2016-do-2020-godine-sa-akcionim. 16.01.2020.

Драгићевић, М. Р., Утвић, М. В. (2019). Умножаване мовираних фемининума на -(к)иња у савременом српском језику. „Српски језик” XXIV, стр. 187-200. https://doi.org/10.18485/sj.2019.24.1.9

Заштитник грађана РС (2010). Упутства за стандардизован недискриминативни говор и понамање.

Ивић, М. (1989). Нека запажања о броју и роду у српскохрватском језику. „Јужнословенски фииолог” књ. XLV, стр. 27-44.

Игњатовић, Т. (ур.) (2018). Нулта толеранција на родно засновано насиље: Приручник за укључиваюе тема родне равноправности и родно заснованог насиља у наставу и ваннаставне активности средюих школа. Београд: Аутономни женски центар.

Клајн, И. (2017). Кад кокош постане петао. „НИН” бр. 3484, 5.10.2017.

Клајн, И. (2018). Девојчица с локницом на челу. „НИН” бр. 3506, 8.03.2018.

Клајн, И. (2020). Мука са суфиксима. „НИН” бр. 3652, 24.12.2020.

Клајн, И. (2021). Родна (не)равноправност. „НИН” бр. 3654, 6.1.2021.

Маринковић, Р.(ур.) (1996). Писах и потписах: аутобиографске изјаве средњег века. Београд : Нолит.

Пешикан, М, Јерковић, Ј., Пижурица, М. (2010). Правопис српскога језика. Нови Сад: Матица српска.

Пипер, П., Клајн, И. (2013). Нормативна граматика српског језика. Нови Сад: Матица српска.

Пипер, П. (2009). Родна равноправност и језик. „НИН” 13.08.2009.

Пипер, П. (2014). О грамматикализации сербских фемининативов. У: П. Пипер, Лингвистичка славистика: студије и чланщи. Београд: Славистичко друштво Србије, стр. 145-159.

Пипер, П. (2016). О социјалним фемининативима у српском и другим словенским језииима. „Јужнословенски филолог” књ. LXXII, св. 3-4, стр. 35-65.

Речник српскохрваткога киижевног језика, т. 1-6 (1967-1976). Нови Сад-Загреб: Матица српска-Матица хрватска.

Речник српскога језика (2011). Нови Сад: Матица српска. 
Ристић, Д. (2019). Однос према мушком и женском роду у Лрпском рјечнику из 1852. године и у Rечнику српскога језика Матице српске. Периепција мушкарцุа и жене некада и сада. [Необјављени мастер рад]. Нови Сад: Филозофски факултет. http://remaster.ff.uns.ac.rs/materijal/punirad/Master_rad_20191022_sjk 230025_2018.pdf. 16.01.2020.

Срдић-Поповић, Ј. (1913). О женским књигама. У: Српкиња: њезин живот и рад, њезин културни развитак и њезина народна умјетност до данас. Ур. српске књижевнице. Сарајево: Пијуковић и друг, стр. 115-125.

Станков, Љ. (2011). Катарина Миловук (1844-1913) и женски покрет у Србији. Београд: Педагошки музеј.

Томин, С. (2007). Кьигољубиве жене српског средюег века. Нови Сад: Академска књига.

Ћорић, Б. (1982). Моциони суфикси у српскохрватском језику. Београд: Филолошки факултет Београдског универзитета.

Ћорић, Б. (2008). Граматички род и питање полне дискриминације у језику. У: Б. Ћорић. Творба именииа у српском језику. Београд: Друштво за српски језик и књижевност Србије, стр. 202-209.

[Antonić, S. (2011). Iskušenja radikalnog feminizma: moć i granice društvenog inženjeringa. Beograd: Službeni glasnik.

Barać, S. (2015). Feministička kontrajavnost: žanr ženskog portreta u srpskoj periodici 1920-1941. Beograd: Institut za književnost i umetnost.

Bošković, V. (2015). Diskurzivna sredstva za izražavanje rodnih ideologija na primeru studentske populacije u Srbiji. [Neobjavljena doktorska disertacija]. Beograd: Filološki fakultet. http://nardus.mpn.gov.rs/bitstream/handle/123456789/6204/Disertacija4128.pdf? sequence=1\&isAllowed=y. 16.01.2020.

Veselinović, M. (1909). Srpske kaluđerice. „Glas srpske kraljevske akademije” knj. LXXX, str. 154-256.

Vlada Republike Srbije (2016). Nacionalna strategija za rodnu ravnopravnost za period od 2016. do 2020. godine. „Službeni glasnik RS” br. 4, 22.01.2016. https:// www.mgsi.gov.rs/cir/dokumenti/nacionalna-strategija-za-rodnu-ravnopravnostza-period-od-2016-do-2020-godine-sa-akcionim. 16.01.2020.

Dragićević, M. R., Utvić, M. V. (2019). Umnožavanje moviranih femininuma na -(k) inja u savremenom srpskom jeziku. „Srpski jezik” XXIV, str. 187-200. https://doi. org/10.18485/sj.2019.24.1.9.

Zaštitnik građana RS (2010). Uputstva za standardizovan nediskriminativni govor i ponašanje. https://www.rodnaravnopravnost.rs/. 16.01.2020.

Ivić, M. (1989). Neka zapažanja o broju i rodu u srpskohrvatskom jeziku. „Južnoslovenski fiiolog" knj. XLV, str. 27-44.

Ignjatović, T. (ur.) (2018). Nulta tolerancija na rodno zasnovano nasilje: Priručnik za uključivanje tema rodne ravnopravnosti $i$ rodno zasnovanog nasilja u nastavu $i$ vannastavne aktivnosti srednjih škola. Beograd: Autonomni ženski centar.

Klajn, I. (2017). Kad kokoš postane petao. „NIN” br. 3484, 5.10.2017. http://www.nin. co.rs/pages/article.php?id=111561. 16.01.2020. 
Klajn, I. (2018). Devojčica s loknicom na čelu. „NIN” br. 3506, 8.03.2018. http://www. nin.co.rs/pages/article.php?id=113797. 16.01.2020.

Klajn, I. (2020). Muka sa sufiksima. „NIN” br. 3652, 24.12.2020.

Klajn, I. (2021). Rodna (ne)ravnopravnost. „NIN” br. 3654, 6.01.2021.

Marinković, R.(ur.) (1996). Pisah i potpisah: autobiografske izjave srednjeg veka. Beograd: Nolit.

Pešikan, M., Jerković, J., Pižurica, M. (2010). Pravopis srpskoga jezika. Novi Sad: Matica srpska.

Piper, P., Klajn, I. (2013). Normativna gramatika srpskog jezika. Novi Sad: Matica srpska.

Piper, P. (2009). Rodna ravnopravnost i jezik. „NIN” 13.08.2009.

Piper, P. (2014). O grammatikalizacii serbskih femininativov. U: P. Piper. Lingvistička slavistika: studije i članci. Beograd: Slavističko društvo Srbije, str. 145159.

Piper, P. (2016). O socijalnim femininativima u srpskom i drugim slovenskim jezicima. „Južnoslovenski fillolog” knj. LXXII, sv. 3-4, str. 35-65.

Rečnik srpskohrvatkoga književnog jezika, 1-6 (1967-1976). Novi Sad-Zagreb: Matica srpska-Matica hrvatska.

Rečnik srpskoga jezika (2011). Novi Sad: Matica srpska.

Ristić, D. (2019). Odnos prema muškom i ženskom rodu u Srpskom rječniku iz 1852. godine $i$ u Rečniku srpskoga jezika Matice srpske. Percepcija muškarca i žene nekada $i$ sada. [Neobjavljeni master rad]. Novi Sad: Filozofski fakultet. http:// remaster.ff.uns.ac.rs/materijal/punirad/Master_rad_20191022_sjk_230025_2018. pdf. 16.01.2020.

Srdić-Popović, J. (1913). O ženskim knjigama. U: Srpkinja: njezin život i rad, njezin kulturni razvitak i njezina narodna umjetnost do danas. Ur. srpske književnice. Sarajevo: Pijuković i drug, str. 115-125.

Stankov, Lj. (2011). Katarina Milovuk (1844-1913) i ženski pokret u Srbiji. Beograd: Pedagoški muzej.

Tomin, S. (2007). Knjigoljubive žene srpskog srednjeg veka. Novi Sad: Akademska knjiga.

Ćorić, B. (1982). Mocioni sufiksi u srpskohrvatskom jeziku. Beograd: Filološki fakultet Beogradskog univerziteta.

Ćorić, B. (2008). Gramatički rod i pitanje polne diskriminacije u jeziku. U: B. Ćorić. Tvorba imenica u srpskom jeziku. Beograd: Društvo za srpski jezik i književnost Srbije, str. 202-209]. 